\title{
\#ArmMeWith: Resources for teacher wellbeing
}

\author{
Christina Naegeli Costa $\cdot$ Nansook Park · Mari Kira
}

\begin{abstract}
With teacher burnout on the rise in the US, this study explores the resources that teachers report to need to buffer the demands of their job and to increase their experience of wellbeing instead of stress and burnout. The data consists of tweets that teachers posted as a part of the \#ArmMeWith Twitter campaign to voice the resource that they need in their job. We used thematic analysis to categorize teacher resource needs from 2,639 tweets. Using the Job Demands-Resources theory (JD-R) of employee wellbeing, we sorted codes into themes (physical, psychological, social, organizational), and investigated resource needs across regions of the United States. In this sample, teachers reported needs in all JD-R resource categories, and we identified an additional theme of institutional resource needs to represent the need for political and social change that teachers reported. In our frequency analysis, the need for physical and organizational resources were the most prevalent, and we found no regional differences. This research contributes to the literature on teacher wellbeing by highlighting resources that have the potential to bolster teacher wellbeing. The research also contributes to the JD-R theory by suggesting that institutional factors may contribute to employee wellbeing.
\end{abstract}

Keywords: teacher wellbeing; job demands-resources; resource needs; qualitative methodology

\section{Introduction}

"\#ArmMeWith an administration that supports us, fair pay, and the autonomy to teach what my students need," a teacher said on Twitter in response to a social media movement that commenced after another tragic school shooting in the United States. On February 14, 2018, a gunman opened fire at a High School in Parkland, Florida. This deadly shooting came at a time of heightened discussion around gun control in the United States. In response, President Donald Trump made several public statements suggesting how to make schools a safer place. During a White House listening session, President Trump stated, "If you had a teacher who was adept with the firearm, they could end the attack very quickly" (Merica \& Klein, 2018).

On social media, teachers responded to such suggestions to arm teachers with guns . A hashtag, \#ArmMeWith, was started by two teachers to provide a forum for teachers to voice their frustrations with the suggestions of being armed, and to discuss their immediate resource needs (Bacon, 2018). Teachers then tweeted to make suggestions for how the money that would be potentially used to arm teachers could alternatively be spent. Within one week, there were over 80,000 uses of the hashtag with these suggestions on Twitter.

Teachers are essential members of the education system, and their wellbeing is of utmost importance in considering the education of future generations. Yet, teaching is considered a 'high-stress' profession (Kyriacou, 2001) with stress often leading to decreases in job satisfaction and commitment and increases in burnout and attrition (Betoret, 2009; Klassen et al., 2013). As

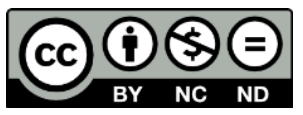

Copyright belongs to the author(s) www.internationaljournalofwellbeing.org 
the educational system and conditions change over time, it is vital to continually study and evaluate teacher stressors and the resources teachers need in coping with these stressors to promote the wellbeing of educators (Kyriacou, 2001). Especially, in the context of the United States, a recent study indicated that $90 \%$ of teachers report experiencing work stress (e.g., Herman et al., 2018), and it is estimated that almost $40 \%$ of teachers leave the profession within the first five years of teaching (Milner \& Woolfolk Hoy, 2003; National Center for Education Statistics, 2004; Educational Commission on Teaching and America's Future, 2004; Smith \& Ingersoll, 2004 as cited in Chang, 2009). Likely adding to teacher stress levels in the United States, they are often asked to train and prepare for a potential active shooter situation, as school shootings are prevalent in the United States (there were 549 reported incidents of gunfire on school grounds from 2013-2019; Everytown for Gun Safety, 2020).

The Job-Demands Resources (JD-R) model posits that both work stress and wellbeing result from the interaction between the demands of a job and its resources. While job demands may create stress, job resources may buffer the job demands, to help employee to reach work goals, stimulate their learning and growth, and help employees experience wellbeing (Bakker \& Demerouti, 2007; Demerouti \& Bakker, 2011). Therefore, understanding the various job resources that teachers need is vital for the improvement of their wellbeing. The JD-R model has been applied to various professional groups, including teachers (Hakanen et al., 2006), but further research is needed to understand the changing and context-specific resource needs of teachers. The current study offers some insights into these teacher resource needs with the help of the Twitter hashtag campaign, \#ArmMeWith.

In this paper, we present the results of a thematic analysis of teachers' \#ArmMeWith tweets to answer four research questions: (1) In the context of this hashtag, what resources do teachers report they need in the workplace?; (2) Which resource needs are reported most frequently?; (3) Do these resource needs differ across regions of the United States?; and, (4) Do the reported resources fit into the original JD-R resource categories? This study, to our knowledge, is one of the first to use Twitter data to examine teacher wellbeing.

\subsection{Job demands, job resources, and teacher wellbeing}

Work stress has negative consequences for teachers' emotional and professional wellbeing (McCarthly et al., 2009) and may even lead to burnout (Maslach et al., 2001). Importantly, teachers' wellbeing affects both student wellbeing and student achievement outcomes (e.g., Geving, 2007; Leighton et al., 2016; Kokkinos, 2007). As teacher burnout and stress increases, teacher attrition increases and and their job satisfaction decreases (Howard \& Johnson, 2004), which negatively impacts on student achievement and student motivation (Ronfeldt et al., 2013; Shen et al., 2015). It is important to find ways to decrease teacher stress and burnout to combat these negative outcomes for teachers and students.

We use the Job-Demands Resources theory (JD-R) to better understand teachers' wellbeing in contemporary United States schools. The JD-R theory defines wellbeing as a state of work engagement-as a positive work-related psychological state characterized by vigor, dedication, and absorption (Schaufeli \& Bakker, 2010). Clearly how well teachers are supported by job resources that help them to manage the job demands of their profession will significantly influence their level of wellbeing.

Job demands are physical, psychological, social, or organizational aspects of work that require physical or psychological efforts that can be associated with physical or psychological costssuch as heavy workload or conflict at work (Demerouti \& Bakker, 2011). Although job demands are not necessarily negative, they become stressors when workers have no resources to recover 
from the demands of their job (Schaufeli \& Bakker, 2004). When it comes to the teacher profession, job demands such as managing negative student behaviors, large class size, insufficient salary, heavy workload, and lack of social support have been recognized as contributors of teacher stress and burnout (Bitsadze \& Japaridze, 2014; Castro et al., 2010; Chang, 2009; Ju et al., 2015; Kyriacou, 2001; Macdonald, 1999; Nagy \& Takács, 2017).

Job resources, on the other hand, refer to the physical, psychological, social, or organizational factors of work that are functional in helping individuals to achieve goals at work, which can alleviate and buffer the physical and psychological costs of job demands, thereby stimulating teacher wellbeing at work (Demerouti \& Bakker, 2011; Schaufeli \& Bakker, 2004). In other words, wellbeing results from workers having resources that help them to cope with and make most out of the high demands of their job. When teachers have been studied within the JD-R framework, job resources that have been identified as supportive of teacher wellbeing include experiencing autonomy at work and opportunities for professional development and teacher training (Simbula et al., 2012). Social support factors also appear to be important job resources to teachers including colleague support, supervisor support, and a positive social support climate at school (Hakanen et al., 2006; Simbula et al., 2012; Williams et al., 2016).

Earlier studies have applied the JD-R model to teachers, and the predicted interactive consequences of job demands and resources on stress and wellbeing have been verified with teacher populations (e.g., Dicke et al. 2018; Evers et al., 2016; Hakanen, et al., Bakker, and Schaufeli 2006). Nevertheless, we propose that further studies are needed to understand the resources that teachers in contemporary American schools need to deal with their demanding jobs.

\subsection{Current study}

The current study uses the Twitter campaign \#ArmMeWith to investigate teacher perceptions of job resource needs, and to group these needs using the JD-R theory resource categories of physical, psychological, social, or organizational resources. Our aim is to offer a unique view of the resources that teacher report they need and also to explore potential further categories of resource needs. When education policies and systems change over time, demands and resources may also change; it is important to investigate teacher wellbeing in the present time due to the changing safety issues that teachers in the United States are navigating as they work in schools. The goal of studying teacher-centered conceptions of what teachers need is to highlight solutions that have the potential to increase teachers' resources, helping them cope better with personal and contextual stressors.

By using Twitter data, this study seeks to understand resources needs directly from teachers who have chosen to voice their concerns. For researchers, social media platforms such as Twitter offer diverse and large sources of data that can be accessed quickly and inexpensively (Jürgens, 2012). Moreover, in an analysis on Twitter data, the themes are discovered in a sample of selfinitiated responses and voluntary disclosure. Research shows that teachers use Twitter for both professional development (Carpenter \& Krutka, 2014) and to experience a sense of community and combat teacher isolation (Wright, 2010). Therefore, Twitter offers a unique platform to investigate teacher conversations online.

\section{Method}

\subsection{Procedure}

Data were downloaded from Twitter using Sysomos software commonly used for gathering 
social media data at the end of 2018. A search query was conducted to select tweets that included '\#ArmMeWith' during the first week at the start of the campaign (February $20^{\text {th }}-27^{\text {th }}, 2018$ ). As Twitter gathers location data based on IP addresses and GPS locations, we were able to include tweets originating only from the U.S. The search resulted in 6,607 tweets. The data included time of Tweet, author ID, author name, author URL, gender, language, state, city, sentiment (positive, negative, and neutral), the Tweet, biography, and post source.

We used Brown et al.'s (2018) methods for cleaning social media data to ensure that the tweets in the data set were all relevant to our search criteria. We used several exclusion criteria during the data cleaning process; e.g., tweets that did not use the \#ArmMeWith hashtag for the original purpose or tweets from news outlets promoting the hashtag were excluded. Most importantly, we read both the tweets and tweeters' Twitter bios to make sure that all tweets were from teachers. Users who self-identified in their tweets or in their twitter bios as other than teachers ("As a principal, \#ArmMeWith...,") were excluded. After cleaning the data based on these criteria, there were 2,639 unique tweets remaining in the data set. The author ID, author name, author URL, city, and biography were removed to anonymize the responses.

\subsection{Participants}

Participants were teachers working in the U.S.. From the gender and location information that was included, the tweets that came from teachers that were $50.7 \%$ female and $26.5 \%$ male. The sample of tweets represented all 50 states of the United States with $20.4 \%$ of the tweets originating from the Midwest, 31.7\% from the South, 21.8\% from the West, and 20.4\% from the Northeast region of the United States.

\subsection{Analysis}

We followed Braun and Clarke's (2006) thematic analysis approach. We first used an inductive approach to code all resource needs appearing in the data and then deductively grouped the codes into themes informed by the resource categories distinguished in the JD-R theory. More precisely, we first read all tweets several times and wrote down initial ideas about resource needs. Next, we developed more formal codes, and the first author and a research assistant (in consultation with the second author) wrote a codebook (Krippendorff, 2019). The codes reflected resources mentioned by the teachers, for example: 'class size' included mentions of smaller class sizes, lower student to teacher ratios, or class size caps; 'pay' included mentions of increases in pay, increases in salary, bonuses, benefits, and pay incentives; and 'training' included mentions of more opportunities for professional development, more teacher training (e.g., English language learners, social emotional learning, math literacy, etc.). The codebook is available by request from the first author. The first author and research assistant conducted three interrater reliability sessions of 100 tweets. The average interrater reliability was excellent (Cohen's $\kappa=.91$ ). Often, teachers listed more than one resource in their tweet, and we coded for different resources mentioned in each tweet, such that any given tweet could have more than one code. This resulted in a total of 5,751 coded excerpts. Then, we conducted a frequency analysis of the resource needs codes. Given that a code could be represented more than one time in a single tweet, we analyzed both the percentage of tweets that contained each code and the percentage of the codes in the total coded items. In other words, we examined how often a resource need was mentioned in all the coded excerpts and also how many tweets mentioned a resource need.

Next, the codes were organized deductively into themes by the first, second, and third author. The JD-R theory categorizes resources needs into physical, psychological, social, and organizational resources (Demerouti \& Bakker, 2011). We grouped the codes into these resources 
needs themes, but also recognized a new theme of institutional resources to represent what teachers tweeted. For example, the codes described earlier (class size, pay, and training) were all groups in the organizational resource theme. To investigate the frequencies by region, we divided the United States into the common geographical regions: Midwest, South, Northeast, and West. We used this data to conduct a frequency analysis of the resource need themes by region. This analysis involved examining the percentages of coded excerpts within each resource needs theme by region. We used a chi-square test of homogeneity to test whether the frequencies of the resource needs themes were distinctly different across regions or whether the variation was due to sampling error.

\subsection{Ethical considerations}

As social media data collection increases in popularity, the ethical questions involved are frequently discussed. Most importantly, the question of participant consent is an area of concern for research using social media. Previous research has argued that Twitter information is public domain, but that identifiable information should be excluded when possible (Shepherd et al., 2015). Following this principle and the related internet ethics guidelines set by the Association of Internet Researchers (www.aoir.org), we removed personal information from the dataset, did not include any Tweets from users with private accounts, and the data was stored under a password protected folder. In addition, it is crucial for a researcher to be mindful of the context in which the social media data was shared (Stewart, 2016) and seek to respect the social media users' intentions for their statements. A researcher should not take a hashtag created by a specific community out of its context and, thereby, potentially misinterpret its meaning to those participating in the conversation. Therefore, we spent a considerable amount of time reading about the ArmMeWith hashtag (e.g., Bacon, 2018; Merica \& Klein, 2018) to ensure that our research is amplifying the voices of the U.S. teacher community.

\section{Results}

\subsection{Resource needs}

We identified 18 resource needs codes and grouped these codes into the JD-R resource themes (social, organizational, psychological, and physical; see Table 1 below). We also identified an additional theme in the analysis - institutional resources - that has not earlier been recognized in the JD-R literature. Then, we investigated the frequency of resource needs in two ways; we counted the number of tweets in which each code was mentioned and also how many times a code was mentioned overall (see Table 2 and Figure 1 below). In this section, we present the results by starting with the resource needs theme that was mentioned the most by teachers and address the subsequent themes in the descending order. Due to space limitations, we present the resource needs that teachers mentioned that have not been distinguished in earlier literature on teacher wellbeing and stress, or that are novel to the JD-R literature. Table 1 presents all resource needs and provides data examples for each resource need.

\subsection{Physical resource needs}

The physical resource needs theme includes teachers' need for material resources and was most frequently reported by teachers: $39.56 \%$ of all the coded excerpts fell within this theme. This theme included the codes of materials, funding, technology, security, and physical space. Materials were mentioned by teachers the most frequently, while security and physical space emerged as novel resource needs. We focus on these three resource needs. 
Figure 1. Percentage of codes by resource need themes

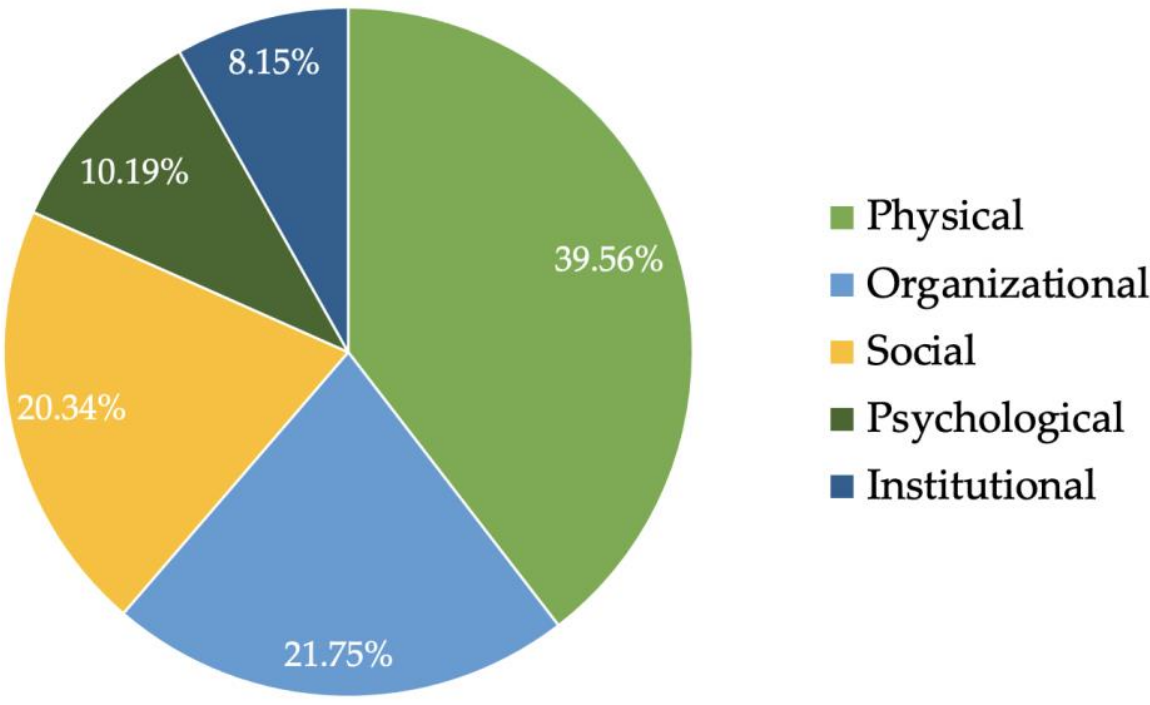

Table 1. Themes, codes, definitions, and example excerpts

\begin{tabular}{|c|c|c|c|}
\hline Theme & Code & Definition & $\begin{array}{l}\text { Example Excerpt } \\
\text { "\#ArmMeWith..." }\end{array}$ \\
\hline \multirow[t]{5}{*}{ Physical } & Materials & $\begin{array}{l}\text { School supplies, curriculum, or } \\
\text { material goods needed for } \\
\text { classroom instruction. }\end{array}$ & "more books" \\
\hline & Funding & $\begin{array}{l}\text { Increases in funding for specific } \\
\text { programs or extracurricular } \\
\text { activities. }\end{array}$ & $\begin{array}{l}\text { "more money for after-school } \\
\text { programs" }\end{array}$ \\
\hline & Technology & $\begin{array}{l}\text { Computers, functioning internet, } \\
\text { and updated building } \\
\text { technology. }\end{array}$ & "internet that always works" \\
\hline & Security $^{*}$ & $\begin{array}{l}\text { Increases in security measures, } \\
\text { including security guards, } \\
\text { security training, and police } \\
\text { officers. }\end{array}$ & "resource officers" \\
\hline & Physical Space & $\begin{array}{l}\text { Improvements in the physical } \\
\text { school building, including } \\
\text { rooms, the exterior building, and } \\
\text { furniture. }\end{array}$ & $\begin{array}{l}\text { "a school with air conditioning } \\
\text { and working heat" }\end{array}$ \\
\hline \multirow[t]{3}{*}{ Organizational } & Time & $\begin{array}{l}\text { More time in the school year, } \\
\text { more time in the school day, or } \\
\text { more time to plan and prepare } \\
\text { for instruction. }\end{array}$ & "more time to prep" \\
\hline & Class Size & $\begin{array}{l}\text { Decreasing the student-teacher } \\
\text { ratio and smaller class sizes. }\end{array}$ & "reasonable class sizes" \\
\hline & Pay & $\begin{array}{l}\text { Increases in wage, more } \\
\text { incentives and bonuses, and } \\
\text { more benefits such as health care } \\
\text { and parental leave. }\end{array}$ & "a livable salary" \\
\hline
\end{tabular}




\begin{tabular}{|c|c|c|c|}
\hline Theme & Code & Definition & $\begin{array}{l}\text { Example Excerpt } \\
\text { "\#ArmMeWith..." }\end{array}$ \\
\hline & Training & $\begin{array}{l}\text { Professional development, } \\
\text { instructional training, and } \\
\text { learning opportunities. }\end{array}$ & "more social-emotional training" \\
\hline & Testing & $\begin{array}{l}\text { Decreases in standardized } \\
\text { testing or increases in alternative } \\
\text { ways to test students. }\end{array}$ & "less standardized testing" \\
\hline & School Culture & $\begin{array}{l}\text { Changes in the ways that schools } \\
\text { function at the school level. }\end{array}$ & $\begin{array}{l}\text { "a school culture based on } \\
\text { character development" }\end{array}$ \\
\hline \multirow[t]{3}{*}{ Social } & $\begin{array}{l}\text { Counseling } \\
\text { Services }^{*}\end{array}$ & $\begin{array}{l}\text { Improvements in mental health } \\
\text { resources, more counselors, } \\
\text { psychologists, and social } \\
\text { workers. }\end{array}$ & $\begin{array}{l}\text { "counselors who have time to } \\
\text { counsel" }\end{array}$ \\
\hline & Social Support & $\begin{array}{l}\text { Support from various } \\
\text { stakeholders, including } \\
\text { administration, colleagues, the } \\
\text { community, and students. }\end{array}$ & "support from my school board" \\
\hline & Support Staff & $\begin{array}{l}\text { Increases in staff positions: } \\
\text { special educators, librarians, } \\
\text { substitute teachers, etc. }\end{array}$ & $\begin{array}{l}\text { "paraprofessionals and special } \\
\text { educators so we can work } \\
\text { together to give support to the } \\
\text { students who need it most" }\end{array}$ \\
\hline \multirow[t]{2}{*}{ Psychological } & $\begin{array}{l}\text { Personal } \\
\text { Strengths* }\end{array}$ & $\begin{array}{l}\text { A response that relates to } \\
\text { personal or individual strengths. }\end{array}$ & "love and patience" \\
\hline & Autonomy & $\begin{array}{l}\text { Teachers making their own } \\
\text { decisions, and trust and respect } \\
\text { to do their job. }\end{array}$ & $\begin{array}{l}\text { "a community that trusts its } \\
\text { teachers" }\end{array}$ \\
\hline \multirow[t]{2}{*}{ Institutional $^{*}$} & $\begin{array}{l}\text { Political } \\
\text { Change }^{*}\end{array}$ & $\begin{array}{l}\text { Legislators and politicians that } \\
\text { understand the needs of teachers } \\
\text { and legislation that supports } \\
\text { teachers and students. }\end{array}$ & $\begin{array}{l}\text { "legislators who actually } \\
\text { understand what educators } \\
\text { need" }\end{array}$ \\
\hline & Social Change* & $\begin{array}{l}\text { Social change in education in } \\
\text { terms of systems of inequity }\end{array}$ & $\begin{array}{l}\text { "leaders that actively work } \\
\text { against systemic racism" }\end{array}$ \\
\hline
\end{tabular}

${ }^{*}$ A new theme/code not mentioned in earlier literature on teacher resources or on the JD-R literature. 
Table 2. Frequencies per total tweets and coded items

\begin{tabular}{|c|c|c|c|c|c|}
\hline Theme & Code & $\begin{array}{l}\text { In how } \\
\text { many } \\
\text { tweets was } \\
\text { the code } \\
\text { mentioned? }\end{array}$ & $\begin{array}{l}\text { Percentage } \\
\text { of all tweets }\end{array}$ & $\begin{array}{l}\text { How many } \\
\text { times was the } \\
\text { code } \\
\text { mentioned? }\end{array}$ & $\begin{array}{l}\text { Percentage of } \\
\text { all coded items }\end{array}$ \\
\hline \multirow[t]{6}{*}{ Physical } & Materials & 1,120 & $42.42 \%$ & 1,626 & $28.27 \%$ \\
\hline & Funding & 303 & $11.48 \%$ & 320 & $5.56 \%$ \\
\hline & Technology & 121 & $4.58 \%$ & 133 & $2.31 \%$ \\
\hline & Security & 104 & $7.58 \%$ & 106 & $1.84 \%$ \\
\hline & Physical Space & 71 & $2.69 \%$ & 90 & $1.56 \%$ \\
\hline & Total & 1,718 & $68.75 \%$ & 2,275 & $39.56 \%$ \\
\hline \multirow[t]{7}{*}{ Organizational } & Time & 391 & $14.81 \%$ & 448 & $7.79 \%$ \\
\hline & Class Size & 267 & $10.11 \%$ & 268 & $4.66 \%$ \\
\hline & Pay & 175 & $6.63 \%$ & 200 & $3.48 \%$ \\
\hline & Training & 122 & $4.62 \%$ & 128 & $2.22 \%$ \\
\hline & Testing & 118 & $4.47 \%$ & 118 & $2.05 \%$ \\
\hline & School Culture & 88 & $3.33 \%$ & 89 & $1.55 \%$ \\
\hline & Total & 1,161 & $43.97 \%$ & 1,251 & $21.75 \%$ \\
\hline \multirow[t]{5}{*}{ Social } & Counseling & 473 & $17.92 \%$ & 642 & $11.26 \%$ \\
\hline & Services & & & & \\
\hline & Social Support & 291 & $11.02 \%$ & 321 & $5.58 \%$ \\
\hline & Support Staff & 188 & $7.12 \%$ & 207 & $3.60 \%$ \\
\hline & Total & 952 & $36.06 \%$ & 1,170 & $20.34 \%$ \\
\hline \multirow[t]{4}{*}{ Institutional } & Political & 227 & $8.60 \%$ & 365 & $6.35 \%$ \\
\hline & Change & & & & \\
\hline & Social Change & 199 & $7.54 \%$ & 221 & $3.84 \%$ \\
\hline & Total & 426 & $16.14 \%$ & 586 & $10.19 \%$ \\
\hline \multirow[t]{4}{*}{ Psychological } & Autonomy & 200 & $7.58 \%$ & 241 & $4.19 \%$ \\
\hline & Personal & 183 & $6.93 \%$ & 228 & $3.96 \%$ \\
\hline & Strengths & & & & \\
\hline & Total & 383 & $14.51 \%$ & 469 & $8.15 \%$ \\
\hline
\end{tabular}


3.2.1 Materials. Teachers indicated the need for materials in their classrooms and schools, such as basic school supplies. Materials were the most mentioned in both categories of frequency analysis (see Table 3). Some teachers tweeted one, specific material object that they needed such as "paper" or "pencils." Other teachers tweeted a list of supplies that they need in their classrooms: "\#ArmMeWith unlimited supplies. Pencils, copy paper, glue, scissors, construction paper, books, printer ink, laminate, binders, folders..." Another teacher listed a similar string of supplies and then stated, "It's sad we supposedly have money for weapons and ammo but not the actual essentials" -indicating that, for them, this list of supplies symbolizes the essential things that were missing. Other material goods that were mentioned included sanitization objects such as "enough Kleenex and hand sanitizer to make it through flu season" and "soap for the bathroom for my students."

3.2.2 Security. Even if not mentioned very often (see Tables 2 and 3), security emerged as a novel resource need not discussed earlier in the literature on teacher wellbeing. Security captured teachers' need for increased security measures in their schools, including security-related staff roles and security training and equipment. Many teachers expressed the need for staff roles to increase safety measures in their schools: "\#ArmMeWith trained security on campus that will place staff \& family at ease." Other teachers mentioned safety plans and security equipment. For example, one teacher mentioned security features that could be added to their school: "I have experienced an active shooter situation in my school building. \#ArmMeWith metal detectors, wands, and a resource office on campus to help students and staff feel safe." Another teacher mentioned specific security training: "ALICE training ${ }^{1}$...\#ArmMeWith a plan to keep as many alive as possible." Lastly, a third teacher mentioned a specific security measure for their classroom: "\#ArmMeWith a classroom door that locks."

3.2.3 Physical Space. Here, the focus is on teachers' need for improvements in physical school buildings, such as improvements to classrooms, updating furniture for learning, and enhancements to the school building. First, physical space emerged as missing spaces for teachers and students. One teacher stated, "\#ArmMeWith...how about a school library?" Other teachers suggested "a new basketball court," "a science lab," and "a working auditorium so that we can create events for students and families." Teachers also brought up building renovation needs such as "building repairs" and "paint to fix the chipping peeling on my classroom walls." Moreover, some teachers mentioned the need for changes in furniture: "\#ArmMeWith desks and chairs that are not broken" or "enough" desks for all of their students. Lastly, teachers discussed basic needs and sanitary complaints. One teacher said, "\#ArmMeWith a roof that doesn't leak, a building without rodents, and clean air vents." Another said, "\#ArmMeWith...mold free classrooms; water fountains that work."

\subsection{Organizational resource needs}

The organizational resource needs theme includes changes to school structure and job-level resource needs. $21.75 \%$ of all the coded excerpts were organizational resource needs. This theme included the codes of time, class size, pay, training, testing, and school culture (for frequencies see Table 2). These Organizational resource needs are very familiar from earlier literature addressing teacher wellbeing and stress (e.g., Castro et al., 2010; Simbula et al., 2012) so we address them here only briefly. Most importantly, the tweets about needs relating to time, class

\footnotetext{
${ }^{1}$ Active shooter training.
} 
size, and testing spoke about teachers' need for organizational conditions enabling them to focus on the delivery of high-quality teaching. In relation to time, one teacher tweeted: "\#ArmMeWith time and resources to truly address the social and emotional needs of my students; time to build relationships with my students, time to help all students find their purpose." Both time and class size were connected to teachers' opportunity to provide individualized consideration to each student: "\#ArmMeWith class sizes that I can spend more time building relationships with each child."

Teachers also tweeted about organizational resources that would satisfy their personal and professional needs, such as "\#ArmMeWith time for self-care." (time), "\#ArmMeWith pay that reflects my Master's degree and 28 years of service" (pay), and "\#ArmMeWith the strength to be a better teacher by going to a National Conference" (training).

\subsection{Social resource needs}

The social resource needs theme includes people whose support teachers need to do their job. $20.34 \%$ of all the coded excerpts were social resource needs. Social resource needs included the codes of counseling services, social support, and support staff (for frequencies see Table 2). While social support and support staff are a recognized resource need for teachers in earlier literature (e.g., Ju et al., 2015; Olsen \& Anderson, 2017), this tweet campaign highlighted counseling services as a novel resource. More precisely, teachers recognized the need to increase the number of counselors, psychologists, and social workers at schools, and the need for a better access to mental health services. This tweet exemplifies both the need for counseling service personnel and access to these services: "\#ArmMeWith resource personnel (school psychologists, family counselors, social workers, guidance counselors) who have reasonable caseloads." Moreover, this teacher described why they want counselors in their school: "\#ArmMeWith enough counselors in my school to help my kids tend to their own social and emotional needs so that I can educate the next generation's citizens effectively." Another teacher asked to be armed with these professionals "to help my student learn how to navigate their complex emotions."

\subsection{Psychological resource needs}

Teachers mentioned their own psychological resources needs in the tweets. The psychological resources related to personal strengths that teachers need in their work and a psychological sense of autonomy to lead their own work. $10.19 \%$ of all the coded excerpts were psychological resource needs (for frequencies see Table 2).

The need for autonomy is a familiar topic in literature on wellbeing and stress among teachers (e.g., Cameron \& Lovett, 2014; Hakanen et al., 2006), so we focus here on the need for personal strengths that seems to be an emerging topic in teacher wellbeing literature. These were often tweeted as single words and word lists that reflected teachers' perceived needs of the personal strengths that their profession required for them to be a good teacher. For example, teachers wanted to be armed with "compassion," "creativity," "strength," "humility," "joy," "courage," and "love", or with many of strengths, such as: "\#ArmMeWith Wisdom, knowledge, insight, empathy, and patience."

\subsection{Institutional resource needs}

The institutional resource needs theme encompasses teachers' need for political and social change and illustrates how the institutional conditions surrounding teachers' work influence their wellbeing (e.g., legislation that supports teachers). Institutional resources needs is a novel theme 
to both the JD-R theory and teacher wellbeing and stress literature. $8.15 \%$ of all the coded excerpts were institutional resource needs.

3.6.1 Political change. Here, the focus is on teachers' need for government-initiated change, such as the need for changes in laws and policies and politicians that support teachers. Some teachers specifically talked about laws. As the hashtag is rooted in the issues of gun violence in schools, it is not surprising that teachers mentioned "common sense laws that protect a safe learning environment." Interestingly, other laws were brought up in the tweets. One teacher tweeted, "\#ArmMeWith...immigration laws so my students can focus on learning instead of stressing that they or their loved ones will be deported." Additionally, teachers discussed specific people in the political sphere. For example, one teacher said, "\#ArmMeWith the assurance that legislators value students' lives over the money of lobbyists." Another teacher spoke more specifically about the connection to education: "\#ArmMeWith lawmakers and policymakers that oversee educational policy who've actually worked in or even been in a public school."

3.6.2 Social change. Social change captured needs regarding inequity and social justice in schools. Social change spoke broadly about inequities that teachers face or notice in their profession. First, teachers using the hashtag talked about students experiencing poverty (e.g., "ample resources for students in poverty"). Specifically, one teacher discussed the need for food and clothing for students: “\#ArmMeWith granola bars and fruit for those who haven't had breakfast...warm clothes for students who have immigrated." Teachers also used the hashtag to call for "support for homeless students" and "the tools to dismantle the school-to-prison pipeline." Although less often, teachers also used the hashtag to call out systemic injustices for teachers. For example, one teacher tweeted, "\#ArmMeWith people in power who respect Black \& Brown teachers...This means actually valuing Teachers of Color AND hiring them in the first place as a start."

\subsection{Regional frequencies}

We investigated the frequencies of resource need themes across geographical regions of the United States (the Midwest, the South, the Northeast, and the West). We examined these frequencies to explore whether there any trends appeared in differences in needs of teachers across regions (see Figure 2 below). Overall, frequencies across regions were similar. The chisquare test of homogeneity was not significant $(p>.05)$, such that the variance of resource need themes across regions did not differ significantly.

\section{Discussion}

Our study has explored teacher-reported resource needs in the context of the \#ArmMeWith hashtag and investigated their overall and regional frequencies. In this discussion, we highlight our novel findings and contributions to both the teacher wellbeing literature and the JD-R literature. We found that teachers addressed all broad resource themes suggested in the JD-R model, but our code-level findings provide important insights into what these resource themes mean to contemporary U.S. teachers (e.g., our findings point to the importance of security as an aspect of physical resource needs). Our findings highlight some resource themes that have been recognized in teacher wellbeing literature, but not addressed in studies on teacher wellbeing building on the JD-R theory (e.g., physical resources) thus expanding the understanding of resource types that need to be paid attention to when studying interactions between teachers' job demands and job resources. We also discovered a new resource theme not previously mentioned in the JD-R literature-institutional resource needs. Institutional resource needs capture the 
changes that teachers reported to need in the political and social systems to secure their wellbeing. Our frequency analysis revealed the importance of physical and organizational resources to teachers, as these were reported most often. Moreover, we found no differences between frequencies of resource need themes by region.

\section{Figure 2. Percentage of resource need themes by region}

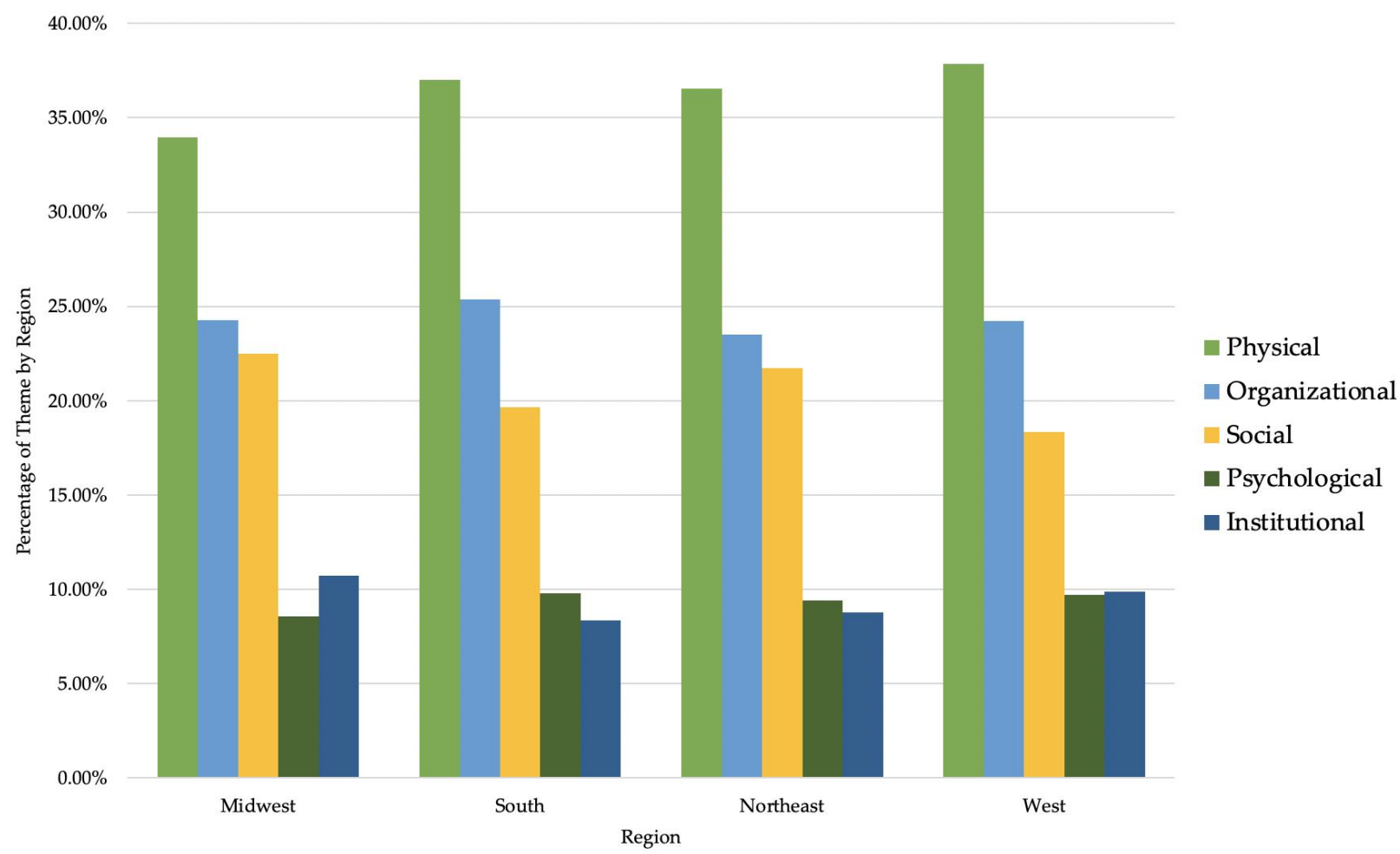

\subsection{Key findings and practical implications}

Our study highlights the variety and frequencies of the physical resource needs that teachers reported. Some physical resource needs have been discussed in conversations surrounding teacher wellbeing (e.g., Education Service Advisory Committee, 1998), but have not yet been categorized as resources in research using the JD-R framework. Materials both for teachers and students was the most frequently mentioned resource need overall and, indeed, materials have been documented in the earlier literature as an important resource for teachers. For instance, the Education Service Advisory Committee (1998) pointed out the need for adequate teacher materials and resources. Other resource needs in this theme, such as the needs concerning the physical space, do not appear as often in the literature on teacher wellbeing. In our results, physical space needs ranged from mold-free classrooms to a library or theatre space in their school. Although these spaces might not be often thought of as factors of teacher wellbeing, this study highlights the unique spaces that teachers need and the quality of these spaces. Researchers may consider how the physical spaces in schools can challenge or support teacher's wellbeing.

The need for security was an interesting finding in our study. To our knowledge, the need for security has not yet been identified as a type of physical resource in the JD-R theory, and neither has it yet been mentioned in the literature on teacher wellbeing. Security is something that teachers think about on the job today, and they reported the need for improved security measures. It is noteworthy that reference to security needs consistently listed other factors than being armed, such as the need for more secure buildings or security plans. There are various 
reasons why teachers may have focused on security in their tweets. This response fits the larger problem that the hashtag tackles and, as many teachers have participated in active shooter trainings, it is possible that security emerged in response to having to think about keeping the classroom safe in the event of an emergency. Nevertheless, according to Maslow (1943), security is an important and fundamental human need. Those concerned with teacher wellbeing could pay particular attention, and further investigate, the growing need of teacher's perceptions of safety in schools.

Organizational resource needs were the second most frequent category of resource needs. Many of these organizational resource needs have been documented in the teacher wellbeing literature. Class size, pay, and career opportunities have been identified as factors that impact teacher attrition (Macdonald, 1999). We also found these factors as important organizational resource needs in our study. Teachers need professional development training, pay that matches their education level, positive changes in school culture, and changes regarding testing in schools. Indeed, some researchers suggest that various types of training (e.g., training on student mental health or professional development for teacher and student wellbeing) should be increased in schools (Schley et al., 2017; White \& Kern, 2018), and research on teachers using JD-R theory also recognizes professional development and training as important resources for teacher wellbeing (Simbula et al., 2012). There is also evidence to suggest that organizational wellbeing training increases the wellbeing of employees (Sutton et al., 2016). In regard to our finding of changes in time, Castro et al. (2010) found that a significant risk factor for teacher wellbeing was a heavy workload (paperwork, meetings, grading). This aligns with teachers reporting the importance and demand of time in the current study. Reorganizing time within the school day or school year could combat the stressor of workload. Exploring how a teacher's time is spent at school and rearranging schedules based on teacher suggestions could likely increase teacher wellbeing.

The third most frequently mentioned resource needs category, social resources, has also been previously highlighted in the teacher wellbeing literature (e.g., Ju et al., 2015; Olsen \& Anderson, 2007) and JD-R literature (e.g., Anderson \& Olsen, 2006; Hakanen et al., 2006). Importantly, social support is negatively associated with teacher burnout and positively associated with teacher retention (Ju et al., 2015; Olsen \& Anderson, 2007). Moreover, a range of social support sources have been identified in the teacher wellbeing literature and as resources in the JD-R modelincluding both administrative support and colleague support (Hakanen et al., 2006; Simbula et al., 2012). In our study, we found that teachers also discussed other staff roles and services that they need. Specifically, counseling services were mentioned by several teachers. The national student to counselor ratio in the United States was 482:1 in the 2014-15 school year, while the national recommended ratio is 250:1 (National Association for College Admission Counseling \& American School Counselor Association, 2015). This suggests that mental health care resources are lacking in schools, and that teachers often may feel like they need to take on this role for students. The lack of counseling services in schools may be an important factor to consider in impacting negatively on teacher wellbeing.

Psychological resource needs have also been highlighted in the literature on teacher wellbeing, and our study confirms the importance of autonomy. Autonomy has also been identified as a resource need in the JD-R literature on teachers (Hakanen et al., 2006). Cameron and Lovett (2014) conducted a study to examine teacher satisfaction over time and found that teachers who were satisfied with their job were the ones who regularly experienced a sense of agency or autonomy. Our research also uncovered personal strengths that teachers indicated they need to do their job effectively - ranging from wisdom to joy, and courage to humility. The need for these personal strengths highlight the socially demanding situations requiring teachers to invest more of 
themselves than simply their professional skills to achieve high-quality professional performance and to maintain their own wellbeing. Few studies have, however, investigated the role of personal strengths for teacher wellbeing (e.g., Chan, 2009), and future research can further explore the role of personal strengths as resources for wellbeing.

We also investigated regional differences in teachers' resource needs. We found that the resource need category frequencies were similar across all regions of the United States. This finding suggests that the common areas of teacher needs are shared rather than unique to any particular regions. Shortage of resources for teachers is a national issue, not regional one. This finding suggests a call for a national attention and effort to address teacher resource needs that will positively impact teachers' lives.

\subsection{Theoretical and methodological implications}

When it comes to the study's theoretical implications, we suggest an extension to the JD-R theory's resource categories: the institutional resource needs. Teachers mentioned institutional resource needs in various ways. For example, teachers noted specific issues that affect teachers of color and the need for more teachers of color in education. This highlights the need to investigate the experience of teachers of color and the added stressors that occur among teachers with these marginalized identities. Additionally, this category of resource needs suggests that teachers are advocating for social changes within schools. Future research may consider social inequities that affect teachers and students. Political change was also a novel resource need in the institutional theme. Like security, political change may have been amplified due to the nature of the hashtag. However, with increasing teacher strikes, politics may play a significant role in how teachers view their profession. Future research should investigate how state and national legislation play a role in teacher wellbeing. Johnson and Down (2013) suggest that research on teacher wellbeing thus far has downplayed the political impact on teachers. They take a socially critical approach to the hyper-individualization of the study of teacher wellbeing and argue that the situational context is important. Our research supports this approach in suggesting that institutional resource needs should be considered when investigating teacher wellbeing.

When it comes to methodological implications, we recognize several benefits of using social media data. The first is the possibility to receive many responses in a short amount of time. Using social media data instantly gave us access to thousands of teacher responses. Next, Twitter data allowed us to avoid some aspects of research bias. While survey and interview questions may prime participants to answer in particular ways, social media data allowed us to investigate spontaneous statements that may represent teachers' genuine thoughts. Finally, this data allowed us to study phenomenon in real-time. Teachers were responding to this hashtag with emotionally laden reactions to the shooting and social media data give us the potential to study these responses. Future research should consider using Twitter data in investigating teacher wellbeing.

\subsection{Limitations}

Our study highlights pressing teacher needs. Although there are many benefits of using Twitter data, there also are some limitations. First, we should consider the Twitter prompt itself. The nature of the hashtag was political. Given the political divide over issues of gun control in the US, it is possible that this sample has some political bias. It is important to consider the teachers who were drawn to this hashtag and how they may differ from those who were not. Moreover, the nature of the hashtag might have swayed the frequency of specific factors. For example, the counseling services theme may have been mentioned more often due to the public conversation of mental health services in schools to approach the mass shooting incidents in the media at the 
time. This hashtag offered a unique insight of teacher resource needs and future studies on teacher resources needs can measure and assess the new and existing resource needs we found through Twitter.

Next, we should consider Twitter users. It is possible that there is something unique about teachers who use Twitter in the first place. According to a survey conducted by the Pew Research Center (2018), twitter users are younger, more educated, and wealthier than the general public. In the context of the current study, this might mean that younger teachers were more likely to respond to the hashtag. In continuing the study of teacher wellbeing, social media data can be a useful way to understand what teachers need, but it is also important to consider the temporal, social and political contexts hashtags being used for data collection and to use other methods of data collection that can allow for random sampling.

\section{Conclusion}

Our study extends the literature of teacher wellbeing by identifying areas of teacher resource needs with social media data. An understanding of these data could improve efforts to address teacher needs and thereby decrease teacher stress and burnout and increase their professional engagement and commitment. This study has important practical, theoretical, and methodological contributions for teacher wellbeing literature. We found a range of teacherreported resource needs-including suggestions that have been well-documented in the literature on teacher wellbeing, but also resource needs that have not been well-documented in the literature. The resource needs that have not previously been well-documented include the need for greater security, more counseling services, social change (e.g., services for marginalized students and teachers), and political change (e.g., laws and lawmakers support teachers). Our study also identified the teachers' need for institutional resources that is often neglected in theories on workplace wellbeing. Theories, research, and practices that address teacher wellbeing should consider and incorporate these novel teacher resource needs to understand teacher wellbeing more comprehensively.

\section{Authors}

Christina Naegeli Costa

University of Michigan

naegeli@umich.edu

Nansook Park

University of Michigan

Mari Kira

University of Michigan

Publishing Timeline

Received 18 August 2020

Revised version received 13 April 2021

Accepted 16 April 2021

Published 31 May 2021 


\section{References}

Anderson, L. \& Olsen, B. (2006). Investigating early career urban teachers' perspectives on and experiences in professional development. Journal of Teacher Education, 57(4), 359-377. https://doi.org/10.1177/0022487106291565

Bacon, J. (2018, February 22). Trump plan at odds with teacher \#ArmMeWith movement. USA Today. https://www.usatoday.com/story/news/nation/2018/02/22/trump-plan-odds-teacher-armmewithmovement/362294002/

Bakker, A.B., \& Demerouti, E. (2007). The Job Demands-Resources model: State of the art. Journal of Managerial Psychology, 22, 309-328. https://doi.org/10.1108/02683940710733115

Betoret, F. D. (2009). Self-efficacy, school resources, job stressors and burnout among Spanish primary and secondary school teachers: A structural equation approach. Educational Psychology, 29(1), 45-68. https://doi.org/10.1080/01443410802459234

Bitsadze, M., \& Japaridze, M. (2014). Personal and social aspects of teacher burnout in Georgia, Problems of Education in the 21 ${ }^{\text {st }}$ Century, 59, 7-14. http://eprints.iliauni.edu.ge/id/eprint/4961

Braun, V., \& Clarke, V. (2006). Using thematic analysis in psychology. Qualitative Research in Psychology, 3(2), 77-101. https://doi.org/10.1191/1478088706qp063oa

Brown, D., Soto-Corominas, A., Surez, J.L., \& de la Rosa, J. (2016). Overview - the social media data processing pipeline. In L. Sloan \& A. Quan-Haase, The SAGE Handbook of Social Media Research Methods (pp. 125-145). London: SAGE. http://dx.doi.org/10.4135/9781473983847

Cameron, M., \& Lovett, S. (2014). Sustaining the commitment and realising the potential of highly promising teachers. Teachers and Teaching, 21(2), 150-163. https://doi.org/10.1080/13540602.2014.928132.

Castro, A. J., Kelly, J., \& Shih, M. (2010). Resilience strategies for new teachers in high-needs areas. Teaching and Teacher Education, 26(3), 622-629.

https://doi.org/10.1016/j.tate.2009.09.010

Carpenter, J. P., \& Krutka, D. G. (2015). Engagement through microblogging: Educator professional development via Twitter. Professional Development in Education, 41(4), 707-728. https://doi.org/10.1080/19415257.2014.939294

Chan, D. (2009). The hierarchy of strengths: Their relationships with subject well-being among Chinese teachers in Hong Kong. Teaching and Teacher Education, 25, 867-875. https://doi.org/10.1016/j.tate.2009.01.010

Chang, M.L. (2009). An appraisal perspective of teacher burnout: Examining the emotional work of teachers. Educational Psychology Review, 21, 193-218. https://doi.org/10.1007/s10648-009-9106-y

Demerouti E., \& Bakker A.B. (2011). The job demands-resources model: Challenges for future research. Journal of Industrial Psychology, 37, 01-09. https://doi.org/10.4102/sajip.v37i2.974

Education Service Advisory Committee. (1998). Managing Work-related Stress: a guide for managers and teachers in the schools (2nd Ed.). London: HMSO.

Evers, A.T., van der Heijden, B.I.J.M., Kreijns, K., \& Vermeulen, M. (2016). Job demands, job resources, and flexible competence: The mediating role of teachers' professional development at work. Journal of Career Development, 43(3), 227-243. https://doi.org/10.1177/0894845315597473

Everytown for Gun Safety. (2020, February 11). Keeping our schools safe: A plan for preventing mass shootings and ending all gun violence in American schools. https://everytownresearch.org/wpcontent/uploads/2020/02/WEB-School-Safety-021120A.pdf

Geving, A. M. (2007). Identifying the types of student and teacher behaviours associated with teacher stress. Teaching and Teacher Education, 23(5), 624-640. https://doi.org/10.1016/J.TATE.2007.02.006

Hakanen, J. J., Bakker, A. B., \& Schaufeli, W. B. (2006). Burnout and work engagement among teachers. Journal of School Psychology, 43(6), 495-513. https://doi.org/10.1016/J.JSP.2005.11.001

Herman, K. C., Hickmon-Rosa, J., \& Reinke, W. M. (2018). Empirically derived profiles of teacher stress, burnout, self-efficacy, and coping and associated student outcomes. Journal of Positive Behavior Interventions, 20(2), 90-100. https://doi.org/10.1177/1098300717732066

Howard, S., \& Johnson, B. (2004). Resilient teachers: Resisting stress and burnout. Social Psychology of Education, 7(4), 399-420. https://doi.org/10.1007/s11218-004-0975-0 
Johnson, B., \& Down, B. (2014). Critically re-conceptualising early career teacher resilience. Discourse: Studies in the Cultural Politics of Education, 35, 5, 703-715. https://doi.org/10.1080/01596306.2013.728365

Ju, C., Lan, J., Li, Y., Feng, W., \& You, X. (2015). The mediating role of workplace social support on the relationship between trait emotional intelligence and teacher burnout. Teaching and Teacher Education, 51, 58-67. https://doi.org/10.1016/j.tate.2015.06.001

Jürgens, P. (2012). Communities of communication: Making sense of the "social" in social media. Journal of Technology in Human Services, 30(3-4): 186-203.

https://doi.org/10.1080/15228835.2012.746079

Klassen, R., Wilson, E., Siu, A. F. Y., Hannok, W., Wong, M. W., Wongsri, N., Sonthisap, P., Pibulchol, C., Buranachaitavee, Y., \& Jansem, A. (2013). Preservice teachers' work stress, self-efficacy, and occupational commitment in four countries. European Journal of Psychology of Education, 28, 1289-1309. https://doi.org/10.1007/s10212-012-0166-x

Kokkinos, C. M. (2007). Job stressors, personality and burnout in primary school teachers. British Journal of Educational Psychology, 77(1), 229-243. https://doi.org/10.1348/000709905X90344

Krippendorff, K. (2018). Content analysis: An introduction to its methodology (4th ed.). Thousand Oaks, CA: Sage.

Kyriacou, C. (2001). Teacher stress: Directions for future research. Educational Review, 53(1), 37-41. https://doi.org/10.1080/0013191012003362

Leighton, J. P., Seitz, P., Chu, M-W., \& Bustos Gomez, M. C. (2016). Operationalizing the role of trust for student wellbeing, learning and achievement. International Journal of Wellbeing, 6(2), 57-79. https://doi.org/10.5502/ijw.v6i2.467

Macdonald, D. (1999). Teacher attrition: a review of literature. Teaching and Teacher Education, 15(8), 835848. https://doi.org/10.1016/S0742-051X(99)00031-1

Maslach, C., Jackson, S. E., \& Leiter, M. P. (1996). Maslach Burnout Inventory manual (3rd ed.). Palo Alto, CA: Consulting Psychologists Press.

Maslach, C., Schaufeli, W. B., \& Leiter, M. P. (2001). Job burnout. Annual Review of Psychology, 52(1), 397422. https://doi.org/10.1146/annurev.psych.52.1.397

Maslow, A. H. 1943. A theory of human motivation. Psychological Review, 50(4), 370-396.

McCarthy, C. J., Lambert, R. G., O'Donnell, M., \& Melendres, L. T. (2009). The relation of elementary teachers' experience, stress, and coping resources to burnout symptoms. The Elementary School Journal, 109(3), 282-300. https://doi.org/10.1086/592308

Merica, D., \& Klein, B. (2018, February 22). Trump suggests arming teaching as a solution to increase school safety. CNN. https://www.cnn.com/2018/02/21/politics/trump-listening-sessions-parklandstudents/index.html

National Association for College Admission Counseling \& American School Counselor Association. (2015). State-by-State student-to-counselor ration report: 10-year trends. https://www.schoolcounselor.org/asca/media/asca/Publications/ratioreport.pdf

Nagy, E., \& Takács, I. (2017). The road to teacher burnout and its possible protecting factors - A narrative review. Review of Social Sciences, 2(8), 9-22. https://doi.org/10.18533/rss.v2i8.107

Olsen, B., \& Anderson, L. (2007). Courses of action: A qualitative investigation into urban teacher retention and career development. Urban Education, 42(1), 5-29. https://doi.org/10.1177/0042085906293923

Pew Research Center. (2018). Sizing up Twitter users. https://www.pewresearch.org/internet/2019/04/24/sizing-up-twitter-users/

Ronfeldt, M., Loeb, S., \& Wyckoff, J. (2013). How teacher turnover harms student achievement. American Educational Research Journal, 50(1), 4-36. https://doi.org/10.3102/0002831212463813

Schaufeli, W.B., \& Bakker, A.B. (2004). Job demands, job resources and their relationship with burnout and engagement: A multi-sample study. Journal of Organizational Behavior, 25, 293-315. https://doi.org/10.1002/job.248

Schley, C., McKay-Brown, L., Ring, J., Monson, K., Robinson, J., Crothers, L., \& Moore, J. (2017).“Time to Reflect": Enhancing the self-efficacy of secondary school wellbeing personnel in recognising and 
responding to mental health needs of students. International Journal of Wellbeing, 7(1), 40-64. https://doi.org/10.5502/ijw.v7i1.484

Shen, B., McCaughtry, N., Martin, J., Garn, A., Kulik, N., \& Fahlman, M. (2015). The relationship between teacher burnout and student motivation. British Journal of Educational Psychology, 85(4), 519-532. https://doi.org/10.1111/bjep.12089

Shepherd, A., Sanders, C., Doyle, M., \& Shaw, J. (2015). Using social media for support and feedback by mental health service users: thematic analysis of a twitter conversation. BMC Psychiatry, 15(1). https://doi.org/10.1186/s12888-015-0408-y

Simbula, S. (2010). Daily fluctuations in teachers' well-being: a diary study using the Job DemandsResources model. Anxiety, Stress \& Coping, 23(5), 563-584. https://doi.org/10.1080/10615801003728273

Simbula, S., Panari, C., Guglielmi, D., \& Fraccaroli, F. (2012). Teachers' well-being and effectiveness: The role of the interplay between job demands and resources" Procedia Social and Behavioral Sciences, 6 , 729-738. https://doi.org/10.1016/j.sbspro.2012.11.467

Stewart, B. (2016). Twitter as a method: Using Twitter as a tool to conduct research. In L. Sloan \& A. Quan-Haase, The SAGE Handbook of Social Media Research Methods (pp. 251-265). London: SAGE Publications Ltd. https://doi.org/10.4135/9781473983847

Sutton, A., Evans, M., Davies, C., \& Lawson, C. (2016). The development and longitudinal evaluation of a wellbeing programme: An organisation case study. International Journal of Wellbeing, 6(1), 180-195. https://doi.org/10.5502/ijw.v6i1.487

White, M. A., \& Kern, M. L. (2018). Positive education: Learning and teaching for wellbeing and academic mastery. International Journal of Wellbeing, 8(1), 1-17. https://doi.org/10.5502/ijw.v8i1.588

Williams, P., Kern, M. L., \& Waters, L. (2016). Inside-out-outside-in: A dual approach process model to developing work happiness. International Journal of Wellbeing, 6(2), 30-56. https://doi.org/10.5502/ijw.v6i2.489

Wright, N. (2010). Twittering in teacher education: Reflecting on practicum experiences. Open Learning: The Journal of Open, Distance and e-Learning, 25(3), 259-265.

https://doi.org/10.1080/02680513.2010.512102 